\title{
Formation Mechanism of Aromatics During Co-pyrolysis of Coal and Cotton Stalk
}

\author{
Chuyang Tang, Jiaxing Zhao, Xianchun $\mathrm{Li},{ }^{*}$ and Jinling Song \\ Pyrolysis experiments were conducted in a tubular furnace from room \\ temperature to $600^{\circ} \mathrm{C}$ at $5^{\circ} \mathrm{C} / \mathrm{min}$, and kept for $15 \mathrm{~min}$. The light tar was \\ then derived from the liquid products of pyrolysis by $n$-hexane supersonic \\ extraction. Gas chromatography-mass spectrometry was employed to \\ analyze the light tars from cotton stalk (CS) pyrolysis, Shenmu coal (SM) \\ pyrolysis, and co-pyrolysis of CS/SM. Microcrystalline cellulose (MCC) \\ was selected as a model compound, and the light tar from co-pyrolysis tar \\ of MCC/SM was investigated for comparison. The results indicated that \\ CS improved the yields and quality of phenols and benzenes in co- \\ pyrolysis tar and that MCC had excellent performance in the formation of \\ mononuclear aromatics during the co-pyrolysis of MCC/SM. Based on the \\ pyrolytic behavior of CS and SM, the mechanisms of aromatic formation \\ were further determined. It was shown that the free radicals that cracked \\ from CS accelerated the formation of aromatics. The alkyl and \\ mononuclear aromatic radicals of CS pyrolysis combined with the radicals \\ from the SM aromatic structure, which then converted to benzenes and \\ phenols. Finally, the most favorable reaction routes of mononuclear \\ aromatics formation were proposed.
}

Keywords: Aromatics; Cotton stalk; Coal; Co-pyrolysis; Aromatic formation

Contact information: School of Architecture and Construction, University of Science and Technology Liaoning, 185\#, Qianshan Road, Liaoning Province 114051, PR China;

*Corresponding author: askd1972@163.com

\section{INTRODUCTION}

Aromatics and their derivatives, such as phenols and benzenes, are important compounds widely used in the chemical industry (Zhao et al. 2010). Biomass has been recognized as an alternative to coal as a renewable source for phenolic production due to its aromatic structure of lignin (Lei et al. 2019). China has abundant biomass and coal, but the direct combustion of crop stalk and coal has caused serious air pollution in recent decades (Malen and Marcus 2017). Additional research has recently focused on the clean utilization of biomass and low-rank coal as alternative fuels (Kabir and Hameed 2017; Morgan, Jr. et al. 2017). Another promising approach that converts biomass and coal is pyrolysis. This is attractive because of the relatively low cost to transform the abovementioned solids into liquid fuels and syngas. The co-pyrolysis of biomass and coal is regarded as one feasible method to produce liquid fuels and high-value-added chemicals through the clean conversion of biomass and coal (Hassan et al. 2016).

Because the $\mathrm{H} / \mathrm{C}$ ratio of biomass is higher than that of coal, early research confirms that biomass acts as a hydrogen donor because it promotes the aromatic formation during co-pyrolysis of biomass and coal (Zhang et al. 2007). Due to marked structural differences between biomass and coal, the synergetic effects in co-pyrolysis were found to be even more complicated than that in the pyrolysis of biomass or coal alone. Related studies 
revealed that the product distribution of co-pyrolysis was essentially determined by the complicated physical-chemical reactions between biomass and coal (Krerkkaiwan et al. 2013; Li et al. 2013). Biomass has evident synergistic effects on the entire co-pyrolysis process, mainly because it is rich in $\mathrm{O}-\mathrm{H}$ and $\mathrm{C}-\mathrm{O}$ groups (Chen et al. 2019). Zhang et al. (2017b) used tetrahydrofuran to extract three kinds of coal with microwave-assisted heating. The results showed that the aromatic nucleus of coal had an increasing effect on the yield and kinds of aromatic compounds from pyrolysis tar. Abdelsayed et al. (2019) revealed the polar groups cracked from biomass promoted the generation of syngas and tar during the co-pyrolysis of pine wood and coal. Yang et al. (2014) found that the synergetic effects between rice husk and lignite affected the composition and content of aromatics in co-pyrolysis, compared with the pyrolytic tar of lignite. The authors' previous study indicated that cotton stalk as an additive notably improved the aromatic yields during the co-pyrolysis of cotton stalk (CS) and Shenmu coal (SM) (Tang and Zhang 2016).

As is well known, aromatic compounds and their derivatives are mainly mononuclear aromatic hydrocarbons (MAHs) in the tar derived from biomass pyrolysis, such as benzenes and phenols. Much literature has documented that MAHs can also be obtained through the pyrolysis of cellulose and hemicellulose. It has been shown that the formation of aromatic compounds in tar has resulted in the interaction of different components during biomass pyrolysis ( $\mathrm{Gu}$ et al. 2013; Abnisa and Wan Daud 2014). Recent research based on co-pyrolysis has paid more attention to the synergetic effect between biomass and coal. Nevertheless, little research has focused on the formation mechanisms of co-pyrolysis products. Because benzenes and phenols are known as the most valuable chemicals in the co-pyrolysis tar of biomass and coal, understanding their formation mechanisms would be beneficial to regulate the co-pyrolysis process and improve tar's content of MAHs. The generation of free radicals was affected by thermal decomposition kinetics, and the product formation was influenced by the chemical kinetics of free radical reactions ( $\mathrm{Li}$ et al. 2017b). The mechanism of aromatic formation in copyrolysis tar could be discussed intensively, as follows, in view of free radical reactions.

In this study, pyrolysis experiments of Shenmu coal (SM), cotton stalk (CS), and their blends were conducted in a tubular furnace. The tar quality was determined by the content of $n$-hexane soluble (HEX) components in the tar. The maximal yield of soluble $n-$ hexane soluble occurred at the CS/SM ratio of 20/100 according to the co-pyrolysis results. The aromatic compounds in HEX were then detected by gas chromatography-mass spectrometry (GC-MS) and compared with the analysis of its results from pyrolytic experiments of CS, SM, and MCC/SM. The possible mechanisms of MAH formation in co-pyrolysis were proposed based on comparisons of the various product distributions of pyrolytic processing.

\section{EXPERIMENTAL}

\section{Raw Materials and Process of Pyrolysis}

Shenmu coal and cotton stalk were chosen as raw materials. The SM was from Shanxi province, China, and CS was collected from local farms (Shanxi Province, China). The air-dried samples of SM and CS were milled and sieved to obtain test samples that were particles sized less than $180 \mu \mathrm{m}$ in diameter. Microcrystalline cellulose (MCC) was chosen as the model compound. The particle size of MCC (AR grade) was less than $60 \mu \mathrm{m}$, and its degree of polymerization was 3000 to 10000. The pyrolysis experiments were 
conducted in a tubular furnace (from room temperature to $600{ }^{\circ} \mathrm{C}$ at $5^{\circ} \mathrm{C} / \mathrm{min}$, then kept 15 min), as was this research group's previous work (Tang et al. 2015). The liquid products were recovered by washing with acetone (AR grade) as a solvent into a round-bottom flask. The water in the liquid products was determined by ASTM D95 (2010). A rotary evaporator was then used to remove the acetone from the obtained washing liquid. Nonpolar and weak-polar compounds were extracted from pyrolysis tar by n-hexane ultrasonicassisted extraction. The results of pyrolysis experiments are presented in Table 1. Because the cellulose content in CS was $45 \% \pm 0.03$, the blending ratio of MCC/SM was $9 / 100$, corresponding to the ratio of CS/SM (20/100) during co-pyrolysis.

Table 1. Product Distribution from Pyrolysis of Different Samples (wt\%, dafa)

\begin{tabular}{|c|c|c|c|c|}
\hline Samples & Tar & n-Hexane Soluble & Water & Char \\
\hline SM & 11.78 & 8.18 & 6.10 & 73.92 \\
\hline $\mathrm{CS} \mathrm{SM}^{\mathrm{b}}$ & 13.73 & 11.13 & 8.65 & 65.52 \\
\hline $\mathrm{MCC} / \mathrm{SM}^{\mathrm{c}}$ & 12.25 & 10.35 & 9.37 & 67.83 \\
\hline CS & 19.46 & 10.74 & 26.84 & 29.21 \\
\hline \multicolumn{2}{|l}{${ }^{\text {a }}$ Dry and ash free basis; ${ }^{\text {b }}$ Blend ratio is $20 / 100 ;{ }^{\mathrm{c}}$ Blend ratio is $9 / 100$} \\
\hline
\end{tabular}

\section{Methods}

$G C$-MS analyses of n-hexane soluble compounds in the pyrolytic tar

The compounds in HEX were then analyzed by gas chromatography-mass spectrometry (GC-MS, Agilent 5975C; Agilent Technologies, Santa Clara, CA, USA). High-purity helium was chosen as the carrier gas. The content of each compound in the HEX was calculated as the relative peak area against the total peak area (excluding that of the solvent) in the total ion chromatogram of GC-MS. The yield of each compound was defined as the mass percentages of the product against the mass of the test sample (dry and ash free basis).

\section{RESULTS AND DISCUSSION}

\section{Aromatic Characteristics in Pyrolytic Tar}

The contents of phenols, naphthalenes phenanthrenes, benzenes, indenes, fluorenes, biphenyls, and anthracenes were calculated by the GC-MS analyses of HEX extracted from pyrolytic tar and shown in Fig. 1. It was apparent that the aromatics and their derivatives of HEX derived from SM pyrolysis tar were different from that of CS pyrolysis tar. The aromatics and their derivatives in the HEX of CS pyrolysis were composed only of benzenes (1.59 wt $\%$, tar), phenols (6.37 wt $\%$, tar), naphthalenes $(0.21$ $\mathrm{wt} \%$, tar) and biphenyls (0.21 wt\%, tar). The aromatics in the HEX from SM pyrolysis tar were primarily MAHs (including benzenes and phenols) and polycyclic aromatic hydrocarbons (PAHs), such as benzenes (3.48 wt \%, tar), phenols (9.42 wt\%, tar), naphthalenes $(6.79 \mathrm{wt} \%$, tar), and phenanthrenes $(6.28 \mathrm{wt} \%$, tar). The HEX from SM pyrolysis tar also contained indenes (1.87 wt \%, tar), fluorenes (1.61 wt \%, tar), and biphenyls (1.27 wt\%, tar). As mentioned above, the aromatic compounds were largely generated from aromatic radicals during pyrolysis. 


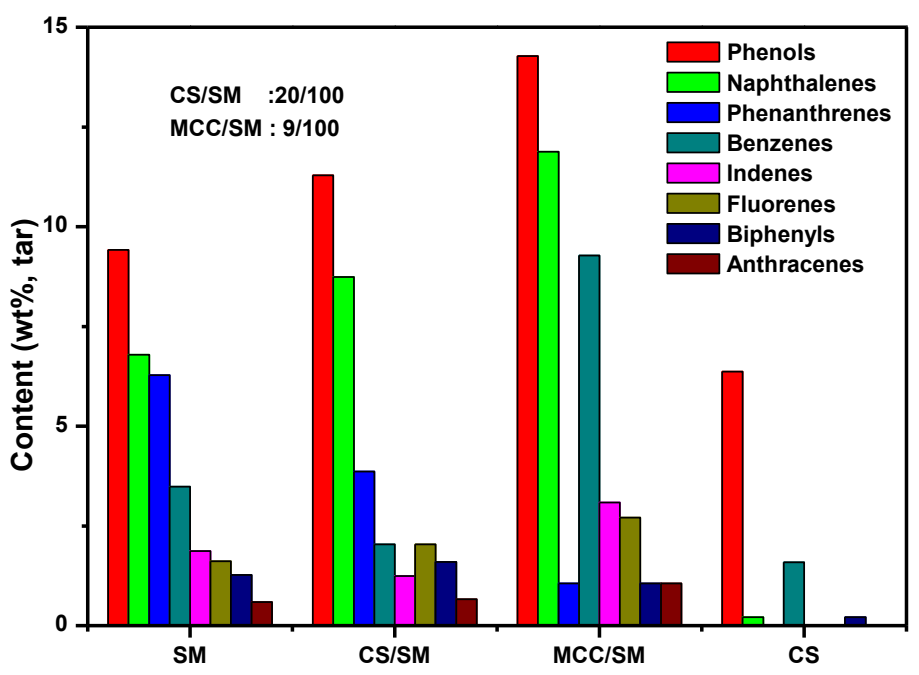

Fig. 1. Aromatic hydrocarbon in n-hexane soluble from pyrolysis tar

As can be seen in Fig. 1, the MAHs contents in the HEX from CS pyrolysis and SM pyrolysis were $11.20 \mathrm{wt} \%$ (tar) and $7.96 \mathrm{wt} \%$ (tar), respectively. The MAHs content in the HEX from CS/SM co-pyrolysis tar was $11.55 \mathrm{wt} \%$ (tar), and as a consequence, higher than its calculated value (10.66 wt\%, tar). It was shown that the effects of the interaction on CS/SM co-pyrolysis can promote the formation of MAHs. Individual MCC pyrolysis has been shown to produce phenols and benzenes, according to some literature (Zhang et al. 2014; Anca-Couce 2016). Figure 1 shows that MCC/SM co-pyrolysis generated far more phenols, benzenes, and naphthalenes than that of CS/SM co-pyrolysis. The contents of phenols and benzenes in the tar of MCC/SM co-pyrolysis were $14.28 \mathrm{wt} \%$ (tar) and 9.28 wt\% (tar), respectively. The MAHs of MCC/SM co-pyrolysis was 76.7\% higher than that of CS/SM co-pyrolysis. Thus, the D-glucose unit depolymerized from cellulose was partly converted to MAHs during MCC/SM pyrolysis. Meanwhile, the alkanes produced by the ring-opening reaction of $\mathrm{D}$-glucose unit were decreased due to the polycondensation of the D-glucose unit, as shown by the authors' previous work (Tang and Zhang 2016). The contents of naphthalenes, indenes, and fluorenes in the tar of MCC/SM co-pyrolysis were consequently more than that of CS/SM co-pyrolysis due to the tautomerization of Dglucose units.

\section{Formation Effects of MAHs and PAHs During Co-pyrolysis}

The chemicals in tar were substantially combined by the interaction of free radicals during pyrolysis. Thus, most aromatics and their derivatives were generated from aromatic radicals. The main components of aromatics and their derivatives in HEX extracted from pyrolysis tar are listed in Table 2. Numbers 1 to 35 are MAHs and Nos. 36 to 64 are multiring hydrocarbons (PAHs). It can be seen that PAHs were not detected in the HEX extracted from CS pyrolysis tar. For the chemical structure difference, CS pyrolysis only released MAH radicals. The thermal decomposition of SM structure produced not only $\mathrm{MAH}$ but also PAH radicals. Coal pyrolysis initially released MAHs at temperatures between 350 and $450{ }^{\circ} \mathrm{C}$, but as the temperature increased, $\mathrm{PAH}$ radicals gradually fell away from the aromatic structure of coal's nucleus (Dong et al. 2012; Lievens et al. 2013). Aromatic radicals readily combined with micromolecular radicals (such as alkyl radical, 
ethyl radical, hydroxyl radical, and so on), which then stabilized into aromatic compounds during pyrolysis.

As shown in Table 2, MAHs in co-pyrolysis tar usually had more than two substituent groups. Electron donating groups such as methyl, methoxy, hydroxy groups would activate the aromatic ring for substitution reaction. For example, the free radicals of methylbenzene generally reacted with micromolecular radicals to be converted to polysubstituted aromatics by electrophilic substitution. In addition, ortho-substituents commonly required less activation energy than para-substituents and meta-substituents during the radical reactions of MAHs formation.

Table 2. Main Components of Aromatics and Its Derivatives in Pyrolysis Tar

\begin{tabular}{|c|c|c|c|c|c|}
\hline \multirow{2}{*}{$\begin{array}{c}\text { Peak } \\
\text { No. }\end{array}$} & \multirow{2}{*}{ Compounds } & \multicolumn{4}{|c|}{ Relative Content (wt\%, tar) } \\
\hline & & SM & $\mathrm{CS}_{\mathrm{SSM}}^{\mathrm{a}}$ & ${\mathrm{MCC} / \mathrm{SM}^{\mathrm{b}}}^{\mathrm{b}}$ & CS \\
\hline 1 & Toluene & 0.44 & 0.34 & 0.27 & 0.41 \\
\hline 2 & Ethylbenzene & 0.17 & 0.15 & - & 0.09 \\
\hline 3 & p-Xylene & 0.82 & - & 0.04 & - \\
\hline 4 & 1,3-dimethylbenzene & 0.16 & 0.62 & 1.28 & 0.31 \\
\hline 5 & 1-ethyl-3-methylbenzene & 0.19 & 0.19 & 0.19 & - \\
\hline 6 & 1-ethyl-2-methylbenzene & 0.17 & 0.17 & 0.53 & 0.08 \\
\hline 7 & 1,2,3-trimethylbenzene & 0.30 & 0.21 & 0.41 & 0.10 \\
\hline 8 & 1,3,5-trimethylbenzene & - & 0.29 & 0.29 & - \\
\hline 9 & 1-ethenyl-2-methylbenzene & - & - & 0.21 & - \\
\hline 10 & Hexylbenzene & - & - & 0.22 & - \\
\hline 11 & 3,5-dimethylbenzaldehyde & - & 0.55 & - & - \\
\hline 12 & 3-methylphenol & 1.91 & 2.02 & 0.12 & 0.31 \\
\hline 13 & 2-methylphenol & 1.23 & 0.82 & 1.81 & 0.31 \\
\hline 14 & 2,4-dimethylphenol & 1.33 & 1.21 & - & 0.37 \\
\hline 15 & 2-ethylphenol & 0.23 & 0.10 & 0.64 & 0.12 \\
\hline 16 & Phenol & 1.15 & 0.94 & 1.97 & 0.20 \\
\hline 17 & 2,6-dimethylphenol & 0.22 & 0.18 & - & 0.12 \\
\hline 18 & 2,3-dimethylphenol & 0.24 & 0.24 & - & - \\
\hline 19 & 4-ethylphenol & 0.24 & - & 0.38 & - \\
\hline 20 & 3-ethylphenol & 0.87 & 1.03 & 1.88 & - \\
\hline 21 & 2-ethyl-4-methylphenol & 0.13 & 0.14 & 0.63 & 0.14 \\
\hline 22 & 3-(1-methylethyl)-phenol & 0.37 & 0.23 & 0.09 & 0.07 \\
\hline 23 & 2,4-bis(1,1-dimethylethyl)-phenol & 0.60 & 0.83 & - & - \\
\hline 24 & 2-methoxy-4-methylphenol & - & 0.39 & - & 0.30 \\
\hline 25 & 2,3,5-trimethylphenol & - & 0.19 & 0.67 & - \\
\hline 26 & 2-methoxy-4-propylphenol & - & 0.45 & - & - \\
\hline 27 & 4-methylphenol & - & - & - & 0.43 \\
\hline 28 & 2-methoxyphenol & - & - & - & 0.63 \\
\hline 29 & 1-(3-methoxyphenyl)-ethanone & - & - & - & 0.40 \\
\hline 30 & 2,6-dimethoxy-4-(2-propenyl)-phenol & - & - & - & 0.37 \\
\hline 31 & 2,3,6-trimethylphenol & - & - & - & 0.35 \\
\hline 32 & 4-ethyl- benzaldehyde & - & - & - & 0.34 \\
\hline 33 & 2,5-dimethylphenol & - & - & 1.89 & - \\
\hline 34 & 3,4-dimethylphenol & - & - & 0.48 & - \\
\hline 35 & 2-ethyl-5-methylphenol & - & - & 0.77 & - \\
\hline
\end{tabular}




\begin{tabular}{|c|c|c|c|c|c|}
\hline 36 & Naphthalene & 0.44 & 0.34 & - & 0.23 \\
\hline 37 & 1-methylnaphthalene & 0.73 & 0.52 & 1.42 & - \\
\hline 38 & 2-methylnaphthalene & 0.50 & 0.76 & - & 0.20 \\
\hline 39 & 2-ethylnaphthalene & 0.25 & 0.26 & 0.48 & - \\
\hline 40 & 1,7-dimethylnaphthalene & 0.32 & - & - & - \\
\hline 41 & 2,3-dimethylnaphthalene & 0.45 & - & 0.70 & - \\
\hline 42 & 2,6-dimethylnaphthalene & 0.33 & 0.43 & 1.32 & - \\
\hline 43 & 1,4-dimethylnaphthalene & - & 0.47 & 0.60 & - \\
\hline 44 & 1,3-dimethylnaphthalene & 0.35 & 0.36 & 1.51 & - \\
\hline 45 & 2,7-dimethylnaphthalene & 0.26 & 0.75 & - & - \\
\hline 46 & 2-(1-methylethyl)-naphthalene & - & - & 0.46 & - \\
\hline 47 & 2,3,6-trimethylnaphthalene & 1.08 & 0.98 & 0.31 & - \\
\hline 48 & 1,6,7-trimethylnaphthalene & - & - & 1.09 & - \\
\hline 49 & $, 1,4,5-$-trimethylnaphthalene & 0.34 & 0.60 & 0.60 & - \\
\hline 50 & 1,4,5,8-Tetramethylnaphthalene & - & 0.51 & - & - \\
\hline 51 & 1,2,3,4-tetramethylnaphthalene & - & - & 0.71 & - \\
\hline 52 & 7-butyl-1-hexylnaphthalene & - & 0.96 & - & - \\
\hline 53 & 2-methylphenanthrene & 0.24 & 0.25 & 0.14 & - \\
\hline 54 & 1-methylphenanthrene & 0.20 & 0.32 & - & - \\
\hline 55 & 1,7-dimethylphenanthrene & 0.32 & - & - & - \\
\hline 56 & 2,3,5-trimethylphenanthrene & 0.65 & 0.68 & - & - \\
\hline 57 & 1-methyl-7-(1-methylethyl)-phenanthrene & 2.13 & 2.40 & 0.77 & - \\
\hline 58 & Phenanthrene & 0.34 & - & - & - \\
\hline 59 & 3-methylphenanthrene & 0.18 & - & - & - \\
\hline 60 & Anthracene & - & 0.41 & 0.49 & - \\
\hline 61 & 2-methylanthracene & 0.22 & 0.24 & - & - \\
\hline 62 & 1-Naphthalenol & 0.19 & 1.16 & - & - \\
\hline 63 & 1-Naphthalenol, 2-methyl- & 0.35 & 0.34 & - & - \\
\hline 64 & 1-Naphthalenol, 4-methyl- & 0.20 & 0.27 & - & - \\
\hline a: blend ratio is 20/100; b: blend ratio is 9/100; - : not detected & & & \\
\hline & & & & & \\
\hline
\end{tabular}

Further analyses indicated that the polysubstituted MAHs in CS pyrolysis tar were more than those in SM pyrolysis tar, and their chemical structure was associated noticeably with biomass pyrolysis. For instance, the methoxyl in 2-methoxyphenol (No. 28) was inherited from lignin. The unsaturated oxygen-containing functional group and the ethyl in 4-ethylbenzaldehyde (No. 32) were derived from the polycondensation of the D-glucose unit in cellulose. Because of the better thermostability of lignin over a wide temperature range, the thermal cleavage of different phenylpropane unites in lignin continuously provided plenty of alkyl and hydroxyl radicals during CS pyrolysis (Yang et al. 2007; Manyà and Arauzo 2008). Compared with individual SM pyrolysis, the more MAH radicals that cracked from SM aromatic nucleus reacted with the alkyl and hydroxyl radicals from lignin decomposition, further generating MAHs during co-pyrolysis of CS and SM (at 20/100 ratio). Therefore, the MAH content in CS/SM co-pyrolysis tar was more than that in individual pyrolysis tar of CS or SM. Furthermore, the phenol content in copyrolysis tar was $9.51 \mathrm{wt} \%$ (tar) and higher than that in SM pyrolysis tar (8.54 wt\%, tar). With the temperature increase, $\mathrm{MCC}$ was depolymerized, and subsequently the ringopening occurred during the co-pyrolysis of MCC and SM. The D-glucose unit in MCC did not form aliphatic hydrocarbons by additional reaction. The D-glucose unit in MCC 
directly converted to phenols by dehydroxylation due to the lack of the methyl radicals derived from lignin pyrolysis. Such type of phenols in MCC/SM co-pyrolysis tar were 2,5dimethylphenol (No. 33) and 2-ethyl-5-methylphenol (No. 35). As a result, the phenols content of MCC/SM co-pyrolysis tar was $14.28 \mathrm{wt} \%$ (tar) and $26.48 \%$ higher than that of $\mathrm{CS} / \mathrm{SM}$ co-pyrolysis tar.

The dissociation and cleavage of raw material structures were generally influenced by thermodynamic factors during the co-pyrolysis of biomass and coal. While the formation and stabilization of co-pyrolysis products were commonly recognized as radical reaction kinetics (He et al. 2014), SM pyrolysis tar had observably more yield and greater variety of PAHs than CS pyrolysis tar in the GC-MS results. Moreover, the HEX from CS pyrolysis tar contained only a small amount of naphthalenes and other kinds of PAHs that were not detected. Because of the chemical structural features of CS, CS pyrolysis could barely produce $\mathrm{PAH}$ radicals. When abundant micromolecular radicals were present in the volatile atmosphere of co-pyrolysis, MAH radicals cannot form PAHs by coupled reaction under the pyrolytic conditions of this study. It was evident that most of the PAHs in CS/SM co-pyrolysis tar were directly generated from PAH radicals released from SM pyrolysis. The PAHs in CS/SM co-pyrolysis tar was $12.35 \mathrm{wt} \%$ (tar), and more than that in SM pyrolysis tar (11.68 wt\%, tar).

The naphthalene content of CS/SM co-pyrolysis tar $(8.74 \mathrm{wt} \%$, tar) was much higher than that of SM pyrolysis tar $(6.79 \mathrm{wt} \%$, tar). Additionally, the naphthol content of co-pyrolysis tar $(1.77 \mathrm{wt} \%$, tar) was also higher than that of SM pyrolysis tar due to the oxygen-containing functional groups rich in CS. The thermal weight loss of MCC mainly occurred in the temperature range of 300 to $400{ }^{\circ} \mathrm{C}$ (Zhang et al. 2017a). The D-glucose unit from MCC depolymerization tended to form MAH in the absence of alkyl radicals during MCC/SM co-pyrolysis. The newly formed MAHs had too high of a reactivity to subsequently couple with the MAH radicals from coal. It was noticed that the naphthalene content of MCC/SM co-pyrolysis was higher than that of CS/SM co-pyrolysis, as shown in Fig. 1.

The generation of phenanthrenes, however, had a different mechanism from that of naphthalenes during co-pyrolysis. The results in Table 2 show that PAHs are mainly were obtained from coal tar, whereas CS pyrolysis cannot produce any PAHs except naphthalenes. Hence, phenanthrenes and anthracenes should be generated only from coal decomposition during co-pyrolysis. The phenanthrene contents of MCC/SM co-pyrolysis and CS/SM co-pyrolysis were $3.86 \mathrm{wt} \%$ (tar) and $6.28 \mathrm{wt} \%$ (tar), respectively. By comparison, SM pyrolysis produced the most phenanthrenes $(6.28 \mathrm{wt} \%$, tar). It was revealed that the additives of CS and MCC could inhibit phenanthrene formation during co-pyrolysis, though they had less effect on the formation of anthracenes. The contents of indenes and fluorenes in CS/SM co-pyrolysis tar were close to that in SM pyrolysis tar. Moreover, indenes and fluorenes were not detected in SM pyrolysis tar. Therefore, indenes and fluorenes were mainly generated from the aromatic radicals of coal during CS/SM copyrolysis.

\section{Generation of Aromatic Radicals During Co-pyrolysis of CS/SM}

Most aromatic compounds were generated from aromatic radicals during CS/SM co-pyrolysis; others were combined by polycondensation of depolymerized cellulose and hemicellulose. Because the chemical structure of CS contained amounts of hydroxyls, CS pyrolysis produced more phenol radicals than SM pyrolysis. The generation of free radicals from SM pyrolysis is shown in Fig. 2. Low molecular compounds and side chains in the 
structure of coal first cleaved to release alkyl radicals at approximately $360{ }^{\circ} \mathrm{C}$ during SM pyrolysis (Liu et al. 2016). Subsequently, the edges of the SM aromatic nucleus started to crack, generating $\mathrm{MAH}$ radicals between 420 and $470{ }^{\circ} \mathrm{C}$ in the pyrolysis process. With increasing pyrolysis temperature, macromolecular fragments fell off from the aromatic nucleus of coal, immediately becoming PAH radicals (Wang et al. 2016). Moreover, the $\mathrm{PAH}$ radicals from coal were the only source of PAHs in CS/SM co-pyrolysis tar.

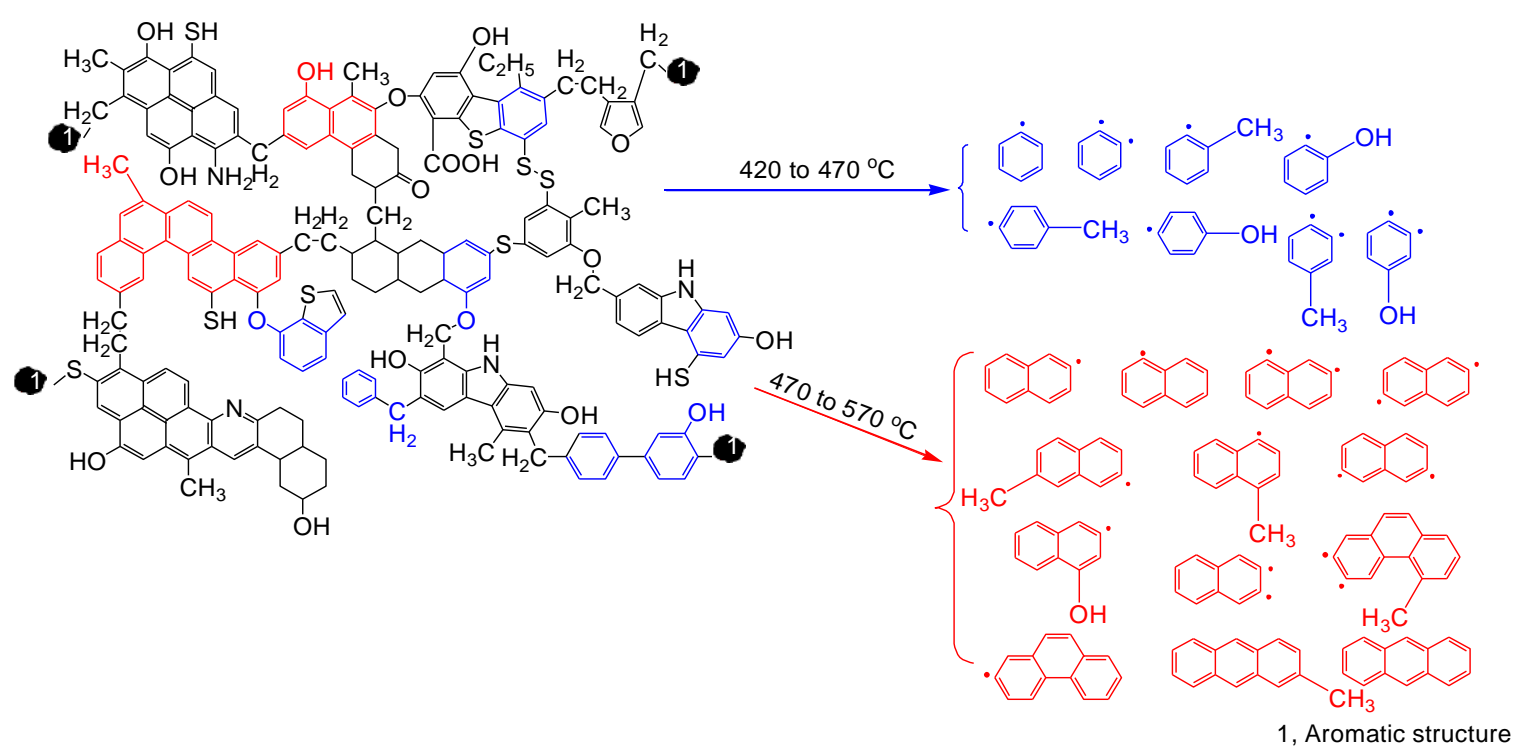

Fig. 2. Generation of aromatic free radicals from SM pyrolysis

The MAH radicals were largely generated from lignin during CS pyrolysis (Jung et al. 2015). Moreover, a few of the MAH radicals had methoxyl groups inherited from lignin in their benzene ring. Because lignin is a type of aromatic high-molecular compound, the chemical structure of lignin is too complex to be expressed accurately by a formula at present. Figure 3 illustrates the generation of aromatic free radicals from lignin during CS pyrolysis. Compared with coal, the chemical structure of lignin is simple and regular. The benzene rings in lignin are joined together by various bridged bonds. With bridged bonds broken, such polymeric structures would gradually decompose and release MAH radicals during CS pyrolysis.

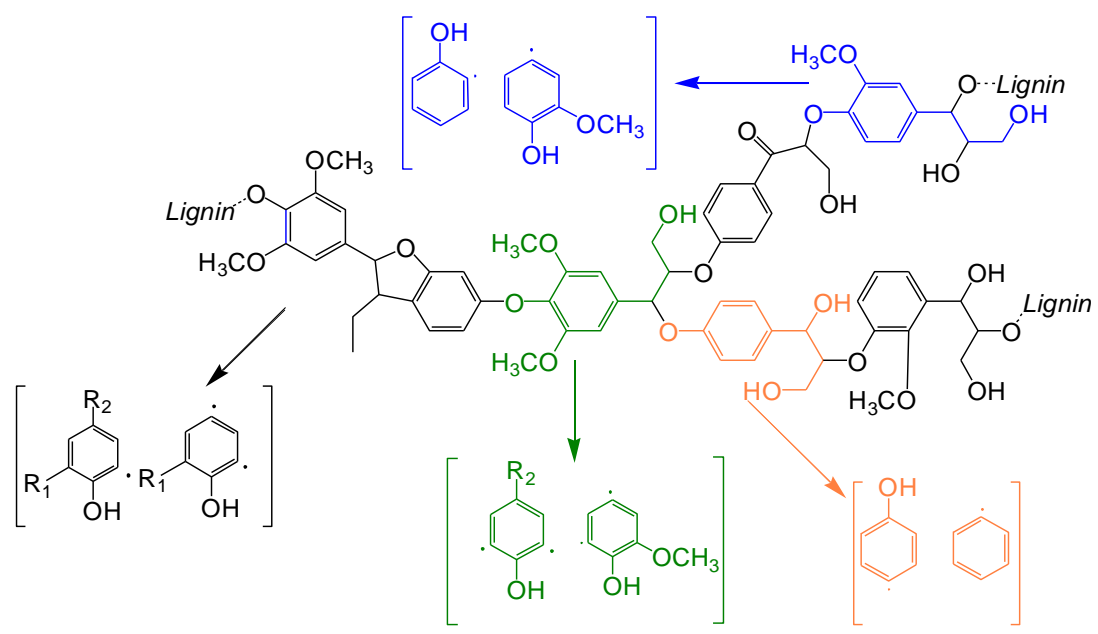

Fig. 3. Generation of aromatic free radicals from lignin during CS pyrolysis 


\section{Reaction Pathway of Aromatic Formation During Co-pyrolysis}

Based on the GC/MS analyses of HEX from tar and the generative process of aromatic radicals, possible synthetic pathways of benzenes were considered as radical reaction during CS/SM co-pyrolysis. As shown in Fig. 4(a through c), benzene radicals combined with methyl and ethyl radicals to form benzenes. In comparison with benzene radicals, methylbenzene radicals more easily generated double-substituted benzene with alkyl radicals due to the existing methyl substituent in the benzene ring. Moreover, the electrophilic substitution commonly occurred in the ortho and para position of the newly formed methylbenzene radical. In SM pyrolysis tar, the content of mono-substituted benzenes was $0.79 \mathrm{wt} \%$ (tar), the content of double-substituted benzenes was $1.38 \mathrm{wt} \%$ (tar), and the content of tri-substituted benzenes was $0.49 \mathrm{wt} \%(\operatorname{tar})$. Benzene formation competed with phenol formation during CS/SM co-pyrolysis. Furthermore, hydroxide radicals showed more reactivity than alkyl radicals to combine with benzene radicals. Because CS produced more oxygenic radicals than SM, the benzene content in CS/SM copyrolysis tar was less than that in SM pyrolysis. In CS/SM co-pyrolysis tar, the content of mono-substituted, double-substituted, and tri-substituted benzenes was $0.50 \mathrm{wt} \%(\operatorname{tar}), 1.01$ $\mathrm{wt} \%(\operatorname{tar})$, and $0.52 \mathrm{wt} \%(\operatorname{tar})$, respectively. Because many hydroxyl radicals were applied to form phenols during CS/SM co-pyrolysis, the generation of pyrolysis water was consequently inhibited.

(a)

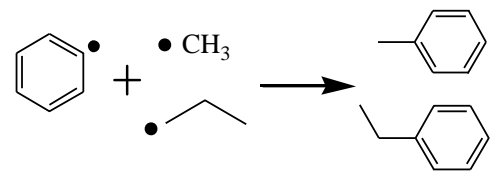

(c)
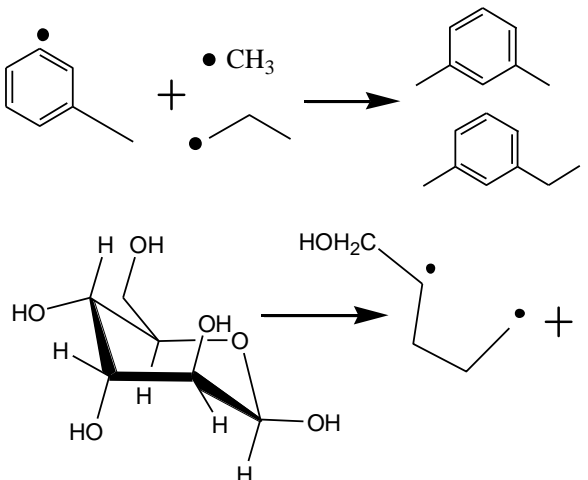

(b)

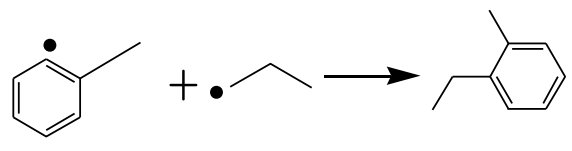

(d)

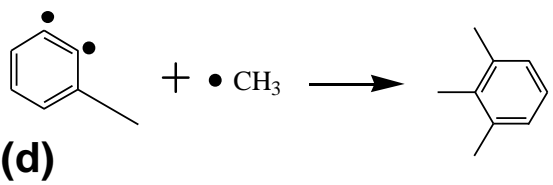

(e)

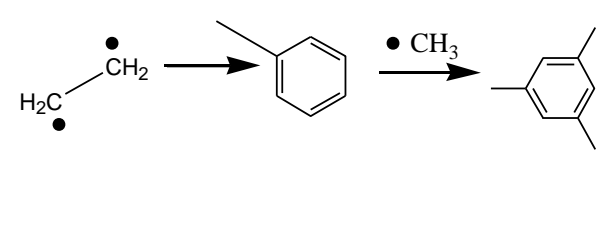

Fig. 4. Synthetic pathway of benzene formation during co-pyrolysis

As can be seen in Fig. 4d, the methylbenzene radical that formed 1,2,3trimethylbenzene (No. 7) was mostly derived from the thermal decomposition of SM aromatic nucleus during CS/SM co-pyrolysis. Under the impact of the existing methyl in the benzene ring, this kind of methylbenzene radical with two lone pair electrons easily trapped methyl radicals, which then were converted to a benzene compound. Because 1,3,5-trimethylbenzene (No. 8 in Table 2) was only detected in CS/SM and MCC/SM copyrolysis, it was indicated that the formation of 1,3,5-trimethylbenzene (No. 8) was greatly affected by the interaction of co-pyrolysis. Because aromatic radicals trapped more alkyl radicals through substitution reactions during co-pyrolysis, some depolymerized D-glucose units of cellulose were selectively converted to MAHs by polycondensation. The MAHs from the polycondensation of the D-glucose unit further combined with methyl radicals to 
form 1,3,5-trimethylbenzene (No. 8), as shown in Fig. 4e. Some literature reported that hemicellulose pyrolysis also produces MAHs (Dussan et al. 2017; Li et al. 2017a).

Table 3. Categories of Phenols in Pyrolysis Tar ( wt\%, tar)

\begin{tabular}{|c|c|c|c|c|}
\hline Samples & Phenols & $\begin{array}{c}\text { Mono-substituted } \\
\text { Phenols }\end{array}$ & $\begin{array}{c}\text { Double-substituted } \\
\text { Phenols }\end{array}$ & $\begin{array}{c}\text { Tri-substituted } \\
\text { Phenols }\end{array}$ \\
\hline SM & 1.22 & 4.76 & 2.37 & 0.19 \\
\hline $\mathrm{CS} \mathrm{SM}^{\mathrm{a}}$ & 0.97 & 3.86 & 4.49 & 0.19 \\
\hline $\mathrm{MCC}^{\mathrm{M}} \mathrm{SM}^{\mathrm{b}}$ & 3.17 & 5.26 & 5.66 & 0.19 \\
\hline${ }^{\mathrm{a}}$ Blend ratio is $20 / 100 ;{ }^{\mathrm{b}}$ blend ratio is $9 / 100$ & \\
\hline
\end{tabular}

The phenols can fall into four categories according to their various number of substituents, as shown in Table 3. The substituents in phenol were alkyls in pyrolysis tar, but a few of them were methoxyl. The content of the phenol with methoxyl was less than $0.5 \mathrm{wt} \%$ (tar) in CS/SM co-pyrolysis tar. Table 3 shows that the content of tri-substituted phenols in the tar of SM pyrolysis, CS/SM, and MCC/SM co-pyrolysis were close. Compared with SM pyrolysis, CS/SM co-pyrolysis produced more double-substituted phenols, while the contents of phenols and mono-substituted phenols in SM pyrolysis tar were higher than that in CS/SM pyrolysis tar. The phenol compounds in tar were largely generated from the phenol radicals during SM pyrolysis due to the better thermal stability of hydroxyl in the aromatic nucleus of coal. Under the influence of hydroxyl in the benzene ring, such phenol radicals combined with alkyl radicals to form phenols with substitutions by electrophilic substitution, as shown in Fig. 5a through b. Some phenols in SM pyrolysis tar were generated from the reactions between benzene and hydroxyl radicals as the synthetic pathway (Fig. 5c). The formation mechanism of partial phenols in CS/SM copyrolysis was the same as that in SM pyrolysis, as shown in Fig. 5a through c. Some phenols with methoxyl were derived from lignin pyrolysis (Fig. 5d), whereas a few of the double-substituted and tri-substituted phenols were generated from cellulose pyrolysis (Fig. 5e). As a result, the phenol content in CS/SM co-pyrolysis tar was $9.51 \mathrm{wt} \%$ (tar) and $11.40 \%$ higher than that in SM pyrolysis tar. Because CS/SM pyrolysis could produce more micromolecular radicals (such as alkyl and hydroxyl radicals) than SM pyrolysis between 420 and $470{ }^{\circ} \mathrm{C}$, the phenol radicals and phenols derived from co-pyrolysis had more selectivity to format the double-substituted phenols. Therefore, the content of doublesubstituted phenols in CS/SM co-pyrolysis tar (4.49 wt\%, tar) was obviously higher than that in SM pyrolysis tar (2.37 wt\%, tar).

All categories of phenol contents in MCC/SM co-pyrolysis were higher in SM pyrolysis than in CS/SM pyrolysis, as shown in Table 3. It was demonstrated that MCC directly produced more phenol compounds due to the lack of interaction with lignin during MCC/SM pyrolysis, compared with that during CS/SM co-pyrolysis. The D-glucose unit from depolymerized cellulose formed ortho or para methylphenol by cracking in a different way. Some of the methylphenols were further converted to double-substituted phenols by electrophilic substitution, as shown in Fig. 5e. The content of phenols in MCC/SM co-pyrolysis tar was 14.28 wt\% (tar) and $67.21 \%$ higher than that in SM pyrolysis tar.

The naphthalenes in CS/SM co-pyrolysis tar were mainly generated from the decomposition of the aromatic nucleus in coal and the coupled reaction of MAH radicals. The above discussion determined that lignin pyrolysis could produce MAH radicals and cellulose pyrolysis could generate MAHs. 
(a)<smiles>CCCC(C)Cc1ccccc1Cc1ccccc1O</smiles>

(c)<smiles>CC(C)(C)c1cccc(C(C)(C)C)c1</smiles>

(b)<smiles>CCc1cccc(O)c1</smiles>

(d)

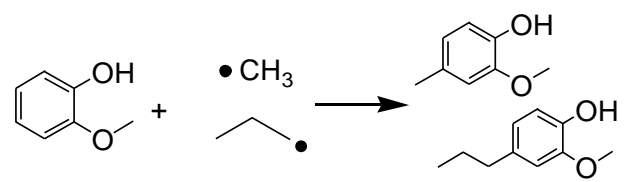

(e)

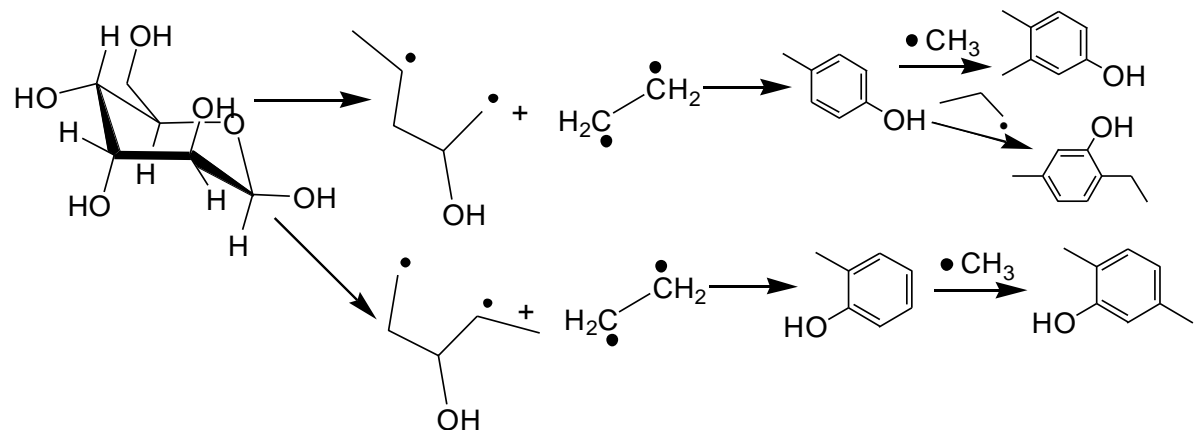

Fig. 5. The synthetic pathways of phenol formation during co-pyrolysis

The content of naphthalenes in the co-pyrolysis tar of CS/SM and MCC/SM was $8.74 \mathrm{wt} \%$ (tar) and $11.88 \mathrm{wt} \%$ (tar), as shown in Table 2, while SM pyrolysis tar contained the lowest naphthalenes content of $6.79 \mathrm{wt} \%$ (tar). Moreover, the content of polysubstituted naphthalenes and naphthols in CS/SM co-pyrolysis tar were observably higher than that in SM pyrolysis tar. It was demonstrated that naphthalenes were largely generated from the coupled reaction of MAH radicals during CS/SM co-pyrolysis. As shown in Fig. $6 a$ through $b$, the newly formed alkylbenzenes combined with each other to form naphthalenes.

(a)

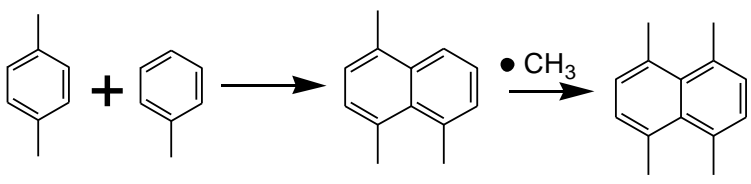

(b)

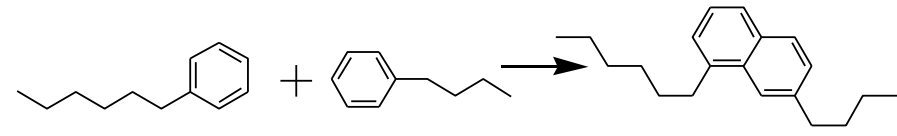

(c)

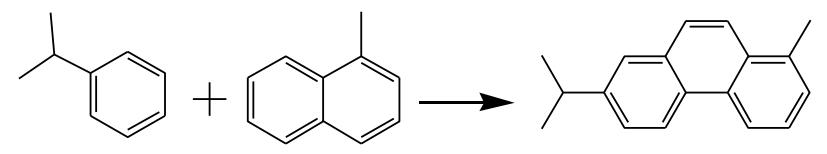

(d)

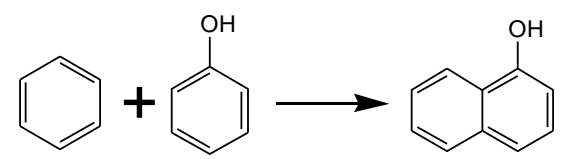

Fig. 6. The synthetic pathways of PHA and its derivatives formation during co-pyrolysis 
The naphthalenes could further combine with alkyl radicals through substitution. The benzenes also coupled with phenols to form naphthols during co-pyrolysis, as can be seen in Fig. 6c. Thus, the naphthol content in CS/SM co-pyrolysis tar was higher than that in SM pyrolysis tar. The content of aromatic compounds in SM pyrolysis tar $(29.61 \mathrm{wt} \%$, tar) was close to that in CS/SM co-pyrolysis, but the content of phenanthrenes in SM pyrolysis tar was $6.28 \mathrm{wt} \%$ (tar), and notably higher than that in CS/SM co-pyrolysis tar (3.86 wt $\%$, tar). The above observation indicated that co-pyrolysis improved the formation of MAHs and inhibited phenanthrene generation, while MCC/SM co-pyrolysis tar contained only $1.06 \mathrm{wt} \%$ (tar) of phenanthrenes. It was further determined that there was competition between the formation of phenanthrene and MAHs during co-pyrolysis. As shown in Fig. 2, the anthracenes were directly derived from coal pyrolysis in view of the similar anthracene content among the tar of SM pyrolysis, and CS/SM and MCC/SM copyrolysis.

\section{CONCLUSIONS}

1. Pyrolysis was conducted in a tubular furnace. There were obvious synergistic effects between biomass and coal during the co-pyrolysis of cotton stalk (CS) and Shenmu coal (SM). Compared with SM pyrolysis, CS/SM co-pyrolysis improved the formation of phenols and naphthalene, while CS as an additive inhibited phenanthrene formation during co-pyrolysis of CS and SM. The mononuclear aromatic hydrocarbons (MAHs) content in the n-hexane soluble (HEX) components from CS/SM co-pyrolysis tar was $11.55 \mathrm{wt} \%$ (tar), and higher than its calculated value (10.66 wt \%, tar).

2. The cellulose significantly promoted the yields of benzenes and phenols in tar during the co-pyrolysis of MCC/SM. The MAHs contents in the tar of MCC/SM co-pyrolysis were 23.56 wt\% (tar), which was $76.74 \%$ higher than that in the tar of $/ \mathrm{SM}$ copyrolysis. The thermal decomposition of D-glucose units obviously accelerated the generation of MAHs during co-pyrolysis.

3. The MAHs in CS/SM co-pyrolysis tar were mainly generated from MAH radicals by substitution. Moreover, the analyses of MCC/SM co-pyrolysis tar indicated that cellulose in CS also produced MAHs through polycondensation. Some naphthalenes in co-pyrolysis tar were largely formed from MAH radicals by a coupling reaction, others were derived from naphthalene radicals, whereas naphthol was mostly formed by the coupling of benzene and phenol. The phenanthrenes and anthracenes directly fell away from the aromatic nucleus of coal during CS/SM co-pyrolysis.

\section{ACKNOWLEDGEMENTS}

The work was supported by the National Key Research and Development Projects of China (No. 2016YFB0600303), the Natural Science Foundation of Liaoning province (No. 20180550636), and the Scientific Research Projects of Institutions of Higher Learning in Liaoning province (No. 2019LNJC14). 


\section{REFERENCES CITED}

Abdelsayed, V., Ellison, C. R., Trubetskaya, A., Smith, M. W., and Dushyant, S. (2019). "Effect of microwave and thermal co-pyrolysis of low-rank coal and pine wood on product distributions and char structure," Energy \& Fuels 33(8), 7069-7082. DOI: 10.1021/acs.energyfuels.9b01105

Abnisa, F., and Wan Daud, W. M. A. (2014). "A review on co-pyrolysis of biomass: An optional technique to obtain a high-grade pyrolysis oil," Energy Conversion and Management 87, 71-85. DOI: 10.1016/j.enconman.2014.07.007

Anca-Couce, A. (2016). "Reaction mechanisms and multi-scale modelling of lignocellulosic biomass pyrolysis," Progress in Energy and Combustion Science 53, 41-79. DOI: 10.1016/j.pecs.2015.10.002

ASTM D95 (2010). "Standard test method for water in petroleum products and bituminous materials by distillation," ASTM International, West Conshohocken, PA, USA.

Chen, X., Liu, L., Zhang, L., Zhao, Y., and Qiu, P. (2019). "Pyrolysis characteristics and kinetics of coal-biomass blends during co-pyrolysis," Energy \& Fuels 33(2), 1267 1278. DOI: 10.1021/acs.energyfuels.8b03987

Dong, J., Li, F., and Xie, K. (2012). "Study on the source of polycyclic aromatic hydrocarbons (PAHs) during coal pyrolysis by PY-GC-MS," Journal of Hazardous Materials 243(12), 80-85. DOI: 10.1016/j.jhazmat.2012.09.073

Dussan, K., Dooley, S., and Monaghan, R. (2017). "Integrating compositional features in model compounds for a kinetic mechanism of hemicellulose pyrolysis," Chemical Engineering Journal 328, 943-961. DOI: 10.1016/j.cej.2017.07.089

Gu, X., Ma, X., Li, L., Liu, C., Cheng, K., and Li, Z. (2013). "Pyrolysis of poplar wood sawdust by TG-FTIR and Py-GC/MS," Journal of Analytical and Applied Pyrolysis 102, 16-23. DOI: 10.1016/j.jaap.2013.04.009

Hassan, H., Lim, J. K., and Hameed, B. H. (2016). "Recent progress on biomass copyrolysis conversion into high-quality bio-oil," Bioresource Technology 221, 645655. DOI: 10.1016/j.biortech.2016.09.026

He, W., Liu, Q., Shi, L., Liu, Z., Ci, D., Lievens, C., Guo, X., and Liu, M. (2014). "Understanding the stability of pyrolysis tars from biomass in a viewpoint of free radicals," Bioresource Technology 156, 372-375. DOI:

10.1016/j.biortech.2014.01.063

Jung, K. A., Woo, S. H., Lim, S. R., and Park, J. M. (2015). "Pyrolytic production of phenolic compounds from the lignin residues of bioethanol processes," Chemical Engineering Journal 259, 107-116. DOI: 10.1016/j.cej.2014.07.126

Kabir, G., and Hameed, B. H. (2017). "Recent progress on catalytic pyrolysis of lignocellulosic biomass to high-grade bio-oil and bio-chemicals," Renewable and Sustainable Energy Reviews 70, 945-967. DOI: 10.1016/j.rser.2016.12.001

Krerkkaiwan, S., Fushimi, C., Tsutsumi, A., and Kuchonthara, P. (2013). "Synergetic effect during co-pyrolysis/gasification of biomass and sub-bituminous coal," Fuel Processing Technology 115, 11-18. DOI: 10.1016/j.fuproc.2013.03.044

Lei, Z., Don, L., Hu, Z., Li, Z. K., Yan, J., Shui, H., Kang, S., Wang, Z., Ren, S., and Pan, C. (2019). "Pyrolysis of acidic ionic liquid [B(SO3H)mim]OTf-treated lignin for phenolics production," Energy \& Fuels 33(6), 4767-4774. DOI:

10.1021/acs.energyfuels.9b00200 
Li, S., Chen, X., Wang, L., Liu, A., and Yu, G. (2013). "Co-pyrolysis behaviors of saw dust and Shenfu coal in drop tube furnace and fixed bed reactor," Bioresource Technology 148, 24-29. DOI: 10.1016/j.biortech.2013.08.126

Li, T., Remón, J., Shuttleworth, P. S., Jiang, Z., Fan, J., Clark, J. H., and Budarin, V. L. (2017a). "Controllable production of liquid and solid biofuels by doping-free, microwave-assisted, pressurized pyrolysis of hemicellulose," Energy Conversion and Management 144, 104-113. DOI: 10.1016/j.enconman.2017.04.055

Li, X. H., Li, L. L., Li, B. F., Feng, J., and Li, W. Y. (2017b). "Product distribution and interactive mechanism during co-pyrolysis of a subbituminous coal and its direct liquefaction residue," Fuel 199, 372-379. DOI: 10.1016/j.fuel.2017.03.004

Lievens, C., Ci, D., Bai, Y., Ma, L., Zhang, R., and Chen, J. Y. (2013). "A study of slow pyrolysis of one low rank coal via pyrolysis-GC/MS," Fuel Processing Technology 116, 85-93. DOI: 10.1016/j.fuproc.2013.04.026

Liu, P., Zhang, D. X., Wang, L. L., Zhou, Y., Pan, T. Y., and Lu, X. L. (2016). "The structure and pyrolysis product distribution of lignite from different sedimentary environment," Applied Energy 163, 254-262. DOI: 10.1016/j.apenergy.2015.10.166

Malen, J., and Marcus, A. A. (2017). "Promoting clean energy technology entrepreneurship: The role of external context," Energy Policy 102(3), 7-15. DOI: 10.1016/j.enpol.2016.11.045

Manyà, J. J., and Arauzo, J. (2008). "An alternative kinetic approach to describe the isothermal pyrolysis of micro-particles of sugar cane bagasse," Chemical Engineering Journal 139(3), 549-561. DOI: 10.1016/j.cej.2007.09.005

Morgan, Jr., H. M., Bu, Q., Liang, J., Liu, Y., Mao, H., Shi, A., Lei, H., and Ruan, R. (2017). "A review of catalytic microwave pyrolysis of lignocellulosic biomass for value-added fuel and chemicals," Bioresource Technology 230, 112-121. DOI: 10.1016/j.biortech.2017.01.059

Tang, C. Y., and Zhang, D. X. (2016). "Mechanisms of aliphatic hydrocarbon formation during co-pyrolysis of coal and cotton stalk," Chinese Chemical Letters 27(10), 16071611. DOI: $10.1016 /$ j.cclet.2016.03.037

Tang, C. Y., Zhang, D. X., and Lu, X. (2015). "Improving the yield and quality of tar during co-pyrolysis of coal and cotton stalk," BioResources 10(4), 7667-7680. DOI: 10.15376/biores. 10.4.7667-7680

Wang, L. L., Pan, T. Y., Liu, P., and Zhang, D. X. (2016). "Hydrogen transfer route during hydrothermal treatment of lignite using the isotope tracer method and improving the pyrolysis tar yield," Energy \& Fuels 30(6), 4562-4569. DOI: 10.1021/acs.energyfuels.6b00281

Yang, H., Yan, R., Chen, H., Lee, D. H., and Zheng, C. (2007). 'Characteristics of hemicellulose, cellulose and lignin pyrolysis," Fuel 86(12-13), 1781-1788. DOI: 10.1016/j.fuel.2006.12.013

Yang, X., Yuan, C., Xu, J., and Zhang, W. (2014). "Co-pyrolysis of Chinese lignite and biomass in a vacuum reactor," Bioresource Technology 173, 1-5. DOI: 10.1016/j.biortech.2014.09.073

Zhang, H., Meng, X., Liu, C., Wang, Y., and Xiao, R. (2017a). "Selective lowtemperature pyrolysis of microcrystalline cellulose to produce levoglucosan and levoglucosenone in a fixed bed reactor," Fuel Processing Technology 167, 484-490. DOI: 10.1016/j.fuproc.2017.08.007

Zhang, L., Hu, S., Chen, Q., Xiao, L., Syed-Hassan, S. S. A., Jiang, L., Wang, Y., Su, S., and Xiang, J. (2017b). "Molecular structure characterization of the tetrahydrofuran- 
microwave-extracted portions from three Chinese low-rank coals," Fuel 189, 178185. DOI: 10.1016/j.fuel.2016.10.082

Zhang, L., Xu, S., Zhao, W., and Liu, S. (2007). "Co-pyrolysis of biomass and coal in a free fall reactor," Fuel 86(3), 353-359. DOI: 10.1016/j.fuel.2006.07.004

Zhang, Y., Liu, C., and Xie, H. (2014). "Mechanism studies on $\beta$-d-glucopyranose pyrolysis by density functional theory methods," Journal of Analytical \& Applied Pyrolysis 105, 23-34. DOI: 10.1016/j.jaap.2013.09.016

Zhao, Y., Deng, L., Liao, B., Fu, Y., and Guo, Q. X. (2010). “Aromatics production via catalytic pyrolysis of pyrolytic lignins from bio-oil," Energy \& Fuels 24(10), 57355740. DOI: 10.1021/ef100896q

Article submitted: February 13, 2020; Peer review completed: April 11, 2020;

Revised version received and accepted: April 25, 2020; Published: April 29, 2020.

DOI: $10.15376 /$ biores. 15.2.4449-4463 